\title{
TAHAPAN PENGEMBANGAN KOLEKSI DISABILITAS DI PERPUSTAKAAN PERGURUAN TINGGI (STUDI KASUS PERPUSTAKAAN UIN SUNAN KALIJAGA YOGYAKARTA)
}

\author{
Riazmi Yusma Sari ${ }^{1}$; Anis Masruri ${ }^{1}$ \\ ${ }^{1}$ UIN Sunan Kalijaga Yogyakarta \\ Korespondensi: riazmiysari@gmail.com
}

Diajukan: 02-10-2020; Direview: 18-10-2020; Diterima: 20-12-2020

\begin{abstract}
The core process of activities in a library is to develop collections for the advancement of knowledge sources. Collection development in this research is in the library of Sunan Kalijaga State Islamic University of Yogyakarta. This study aims to determine the stages of collection development at the UIN Sunan Kalijaga Yogyakarta library, and its object, namely students with disabilities. This research uses a qualitative research method with a descriptive approach. Data collection techniques used in this study were through observation and interviews. Observations were carried out by directly jumping into the field to explore information related to the stages of collection development, and interviews were conducted with Mrs. Dra. Ida Nor'aini Hadna, M.Pd (Kobid Technical Services) and Isrowiyanti (Information Kour). Based on this research, it was concluded that the stages of collection development offered by Evans with 6 components of activities consisting of community analysis in this case the user community, selection policy, selection, procurement, weeding, and evaluation. This theory is applied in the Sunan Kalijaga UIN Yogyakarta library. Normal students and people with disabilities at UIN Sunan Kalijaga Yogyakarta have the same knowledge needs, grouped in the same class. But in this case what distinguishes it is the way to access that is done by students with disabilities with the addition of assistance through audio and visual media and others.
\end{abstract}

Keywords: Sunan Kalijaga Yogyakarta UIN Library, Collection Development, Disability.

\begin{abstract}
ABSTRAK
Proses inti dari kegiatan pada sebuah perpustakaan adalah mengembangkan koleksikoleksi demi kemajuan sumber pengetahuan. Pengembangan koleksi pada penelitian ini yaitu pada perpustakaan UIN Sunan Kalijaga Yogyakarta. Penelitian ini bertujuan untuk mengetahui tahapan-tahapan pengembangan koleksi pada perpustakaan UIN Sunan Kalijaga Yogyakarta, dan objeknya yaitu mahasiswa disabilitas. Penelitian ini menggunakan metode penelitian kualitatif dengan pendekatan deskriptif. Tehnik pengumpulan data yang digunakan dalam penelitian ini adalah melalui observasi dan wawancara. Observasi dilakukan dengan cara terjun langsung kelapangan untuk menggali informasi terkait dengan tahapan pengembangan koleksi, dan wawancara dilakukan dengan ibu Dra. Ida Nor'aini Hadna, M.Pd (Kobid Layanan Teknis) dan Isrowiyanti (Kour Informasi). Berdasarkan penelitian ini, diperoleh kesimpulan bahwa tahapan pengembangan koleksi yang ditawarkan oleh Evans dengan 6 komponen kegiatan yang terdiri dari Analisis masyarakat dalam hal ini masyarakat pengguna, kebijakan seleksi, seleksi, pengadaan, penyiangan, dan evaluasi. Teori ini
\end{abstract}


diterapkan di perpustakaan UIN Sunan Kalijaga Yogyakarta. Mahasiswa yang normal dan penyandang disabilitas di UIN Sunan Kalijaga Yogyakarta memiliki kebutuhan pengetahuan yang sama, dikelompokkan dalam kelas yang sama. Namun dalam hal ini yang membedakannya adalah cara mengakses yang dilakukan oleh mahasiswa disabilitas dengan penambahan bantuan yaitu melalui media audio dan visual dan lainnya.

Kata Kunci: Perpustakaan UIN Sunan Kalijaga Yogyakarta, Pengembangan Koleksi, Disabilitas.

\section{PENDAHULUAN}

Memperoleh informasi yang diolah menjadi ilmu pengetahuan merupakan hak semua orang, baik yang terbilang normal dan bahkan berkebutuhan khusus. Memperoleh informasi tersebut dapat melalui beberapa cara dan melalui beberapa lembaga salah satunya adalah perpustakaan, baik perpustakaan Sekolah Dasar dan bahkan perpustakaan Perguruan Tinggi. Dalam Undang-Undang Dasar 1945 sudah mengatur tentang persamaan hak bagi setiap individu tanpa terkecuali untuk mendapatkan dan memperoleh informasi.

Hak yang dijamin salah satunya yaitu untuk mendapatkan informasi terhadap individu/sekelompok orang yang berkebutuhan khusus. Ini merupakan suatu tantangan bagi sebuah perguruan tinggi untuk menyediakan informasi. Karena keterbatasan fisik para pengguna (user) disabilitas, maka penyediaan serta penyampaian informasi dianggap perlu diperhatikan dan adanya suatu perbedaan. Perbedaan tersebut termasuk kedalam sebuah layanan serta penyediaan koleksi terhadap pemustaka.

Seiring berjalannya waktu dan perkembangan zaman, penyediaan koleksi pada perpustakaan perguruan tinggi terkhusus untuk para disabilitas yang memiliki kebutuhan khusus memiliki perkembangan yang lebih maju demi kemudahan para user untuk mengakses informasi. Pada beberapa perguruan Tinggi, sudah banyak melirik kearah disabilitas yang dianggap sama mempunyai hak dengan mahasiswa/pengguna lainnya yang normal. Dengan itu, maka disediakan dan dikembangkanlah koleksi perpustakaan yang lebih baik lagi.

Namun dalam ruang lingkup pengembangan koleksi di perpustakaan untuk mahasiswa disabilitas merupakan tugas penting yang harus di perhatikan, karena harus adanya penyebaran informasi akademik secara merata untuk seluruh mahasiswa UIN Sunan Kalijaga Yogyakarta. Untuk merealisasikan hal tersebut maka hal penting yang harus diperhatikan yaitu adanya sinergitas antara pihak institusi khususnya pada bagian perpustakaan untuk kemajuan pengembangan koleksinya. Maka dalam artikel ini akan dijelaskan tahapan pengembangan koleksi perpustakaan UIN Sunan Kalijaga untuk mahasiswa disabilitas.

\section{METODE PENELITIAN}

Metode pengumpulan data yang dilakukan dalam penelitian ini adalah melalui observasi, dan wawancara. Penelitian ini dilakukan dengan metode penelitian kualitatif pendekatan deskriptif. Observasi merupakan cara pengumpulan data dengan melakukan pengamatan secara langsung. Wawancara merupakan cara pengumpulan data dengan cara tanya jawab dengan kepala perpustakaan dan staf perpustakaan. Namun dalam hal ini, kepala perpustakaan mengarahkan peneliti untuk wawancara dengan Kobid Layanan Teknis dan Kaur Informasi yaitu Dra. Ida Nor'aini Hadna, M.Pd (Kobid Layanan Teknis) dan Isrowiyanti (Kour Informasi). Objek yang menjadi kajian dalam penelitian ini yaitu kegiatan pengembangan koleksi yang dilakukan pada perpustakaan UIN Sunan Kalijaga Yogyakarta 
dengan subjek penelitian yaitu mahasiswa disabilitas.

\section{KAJIAN TEORI}

Sebuah penelitian yang baik adalah penelitian yang memiliki kerangka teori. Agar pembahasannya lebih terarah dan ditunjang oleh teori-teori dalam pembahasan dan penyelesaian masalah. Pada penelitian ini, penulis menggunakan tiga kerangka teori, yaitu Perpustakaan Perguruan Tinggi, Pengembangan Koleksi dan Disabilitas.

\section{Perpustakaan Perguruan Tinggi}

Perpustakaan Perguruan Tinggi adalah Perustakaan yang mencakup universitas, sekolah tinggi, institut, akademika, dan lain sebagainya yang berada di lingkungan kampus serta pemakainya adalah civitas akademika perguruan tinggi tersebut. Tugas dan fungsi utama Perpustakaan Perguruan Tinggi adalah menunjang proses pendidikan, penelitian dan pengabdian kepada masyarakat atau dalam kata lain yaitu menjalankan tri dharma perguruan tinggi. ${ }^{1}$

Sarana penunjang dalam kegiatan Civitas Akademika pada sebuah Perguruan Tinggi adalah dengan adanya perpustakaan Perguruan Tinggi tersebut. Dalam Undangundang Republik Indonesia No.43 tahun 2007 tentang Perpustakaan mencakup beberapa ayat tentang perpustakaan perguruan Tinggi, diantaranya adalah: ${ }^{2} 1$ ). Setiap perguruan tinggi menyelenggarakan perpustakaan yang memenuhi standar nasional perpustakaan dengan memperlihatkan Standar Nasional Pendidikan. 2). Perpustakaan sebagaimana dimaksud pada ayat (1) memiliki koleksi, baik jumlah judul maupun jumlah eksemplarnya, yang mencukupi untuk mendukung pelaksanaan pendidikan, penelitian, dan pengabdian kepada masyarakat. 3). Perpustakaan perguruan

1 Sutarno NS, Manajemen Perpustakaan: Suatu Pendekatan Praktik, (Jakarta: Sagung Seto, 2006), 35-36.

2 Undang-Undang Republik Indonesia Nomor 43 Tahun 2017 tentang Perpustakaan, Bagian Keempat, Pasal 24. tinggi mengembangkan layanan perpustakaan berbasis teknologi informasi dan komunikasi. 4). Setiap perguruan tinggi mengalokasikan dana untuk pengembangan perpustakaan sesuai dengan peraturan perundang-undangan guna memenuhi standar nasional pendidikan dan standar nasional Perpustakaan.

Perpustakaan perguruan tinggi yang berada di perguruan tinggi tentunya mempunyai tujuan yang lebih khusus dari tujuan perguruan tingginya. Secara umum tujuan perpustakaan tinggi adalah memenuhi keperluan informasi masyarakat perguruan tinggi yaitu mahasiswa, dosen, staf administrasi dan masyarakat luar yang ingin mencari informasi.

Perpustakaan Perguruan Tinggi Menyediakan ruang baca dan belajar untuk pengguna perpustakaan. Selain itu juga perpustakaan Perguruan Tinggi menyediakan proses pinjam buku sebagai sarana informasi bagi seluruh pengguna perpustakaan perguruan tinggi.

Setelah adanya tujuan dari perpustakaan Perguruan Tinggi yang penulis jabarkan diatas, maka disini penulis akan menjabarkan fungsi Perpustakaan Perguruan Tinggi, yaitu:

Pertama, perpustakaan sebagai sumber belajar para user atau pengguna yaitu para civitas akademika (edukasi). Penyediaan koleksi yang ada di perpustakaan yaitu untuk mendukung tercapainya tujuan pembelajaran, pengelompokkan atau pengorganisasian bahan pembelajaran demi perkembangan sumber ilmu pengetahuan bagi para pengguna serta mendukung dalam proses evaluasi pembelajaran.

Kedua, perpustakaan sebagai sumber informasi yaitu pusat temu kembali informasi yang mudah diakses oleh pengguna. Pada fungsi ini, peran perpustakaan dihadirkan untuk menjadi penghubung antara pengguna dan bahan pustaka. Agar seluruh akademika dapat dengan mudah memperoleh informasi demi meratanya sumber pengetahuan. 
Ketiga, perpustakaan berperan sebagai media riset atau penelitian. Perpustakaan dijadikan media rujukan bagi seluruh akademika karena koleksi-koleksi di perpustakaan menyediakan bahan-bahan utama maupun penunjang yang berupa buku-buku utama, jurnal-jurnal ilmiah, dan tulisan-tulisan hasil penemuan oleh peneliti. Sehingga dalam hal ini, bisa menjadikan mahasiswa dan seluruh akademika mengembangkan penelitian baru dengan merujuk kepada hasil penelitian yang sudah ada yang di sediakan oleh perpustakaan.

Keempat, perpustakaan sebagai wadah rekreasi karena perpustakaan menyediakan koleksi-koleksi yang bersifat menghibur bagi pengguna yang anak-anak,remaja, dewasa dan bahkan manula. Koleksi tersebut seperti cerita bergambar, novel, majalah dan lain sebagainya. Koleksi yang disediakan di perpustakaan perguruan tinggi seperti novel yang dapat membawa pembaca dalam imajinasi penulis dan juga untuk koleksi yang kreatif dapat menumbuh kembangkan kreativitas akademika.

Kelima, perpustakaan sebagai wadah publikasi hasil tulisan atau karya ilmiah yang dilakukan oleh akademika lainnya. Dalam ranah publikasi ini, perpustakaan juga memberikan keuntungan atau profit bagi penulis dan deposit bagi seluruh civitas akademika maupun staf non-akademik.

Berdasarkan penjabaran di atas, dapat disimpulkan bahwa pada dasarnya tujuan daripada perpustakaan perguruan tinggi adalah mendukung kinerja dari perguruan tinggi dalam menyelenggarakan pendidikan dengan menyediakan sumber-sumber informasi ilmiah di perpustakaan tersebut dan selalu melayani penggunanya yakni mahasiswa selama menjalankan pendidikan di perguruan tinggi yang bersangkutan. ${ }^{3}$

3 Perpustakaan Universitas Nahdatul Ulama Surabaya, "Tujuan dan Fungsi Perpustakaan Perguruan Tinggi," (20 Oktober 2016), di akses dari https://library.unusa. ac.id/2016/10/20/tujuan-dan-fungsi-perpustakaanperguruan-tinggil, diakses pada 18 Oktober 2019, jam 20.31.
Dilihat dari konsep manajemen, perpustakaan Perguruan Tinggi memiliki tujuan yang dapat disusun secara hierarki, yaitu misi (missioni), sasaran (goals), tujuan (objective), kegiatan (activities), dan program (programmes). ${ }^{4}$

Perpustakaan perguruan tinggi merupakan suatu sistem, dimana secara keseluruhan harus berjalan dengan baik, jika bagian pengadaan bahan pustaka ada masalah, dampaknya akan terasa pada bagian pengolahan, kebagian pelayanan dan kepada bagian lainnya. Antara satu dan keseluruhan saling berkaitan, hingga menyebabkan sistem ini sangat perlu diperhatikan. ${ }^{5}$

\section{Pengembangan Koleksi}

Pengembangan koleksi merupakan kegiatan untuk menghasilkan bahan pustaka baru di perpustakaan berdasarkan hasil seleksi dan evaluasi bahan pustaka serta menunjang teori-teori yang diperlukan. Kegiatan pengembangan ini melibatkan staf perpustakaan, para profesor, para peneliti, pemustaka/pengguna perpustakaan. ${ }^{6}$ Pengembangan koleksi perpustakaan mencakup: a). Jumlah, mencakup judul, jenis dan eksemplar, b).terbitan baru, c). Variasi, baik yang tercetak seperti buku,majalah, koran, maupun yang terekam, d). Sumber penerbitnya, makin banyak, e). Sumber asalnya, dalam negeri (bahasa Indonesia dan bahasa daerah), dari luar negeri, terjemahan, saduran bahasa Inggris dan bahasa lainnya. ${ }^{7}$

4 Syihabuddin Qalyubi dkk, Dasar-dasar IImu Perpustakaan dan Informasi, (Yogyakarta: Jurusan IImu Perpustakaan dan Informasi Fakultas Adab, 2003), 11.

5 Anwar Syamsudin, "Manajemen dan Peran Perpustakaan Perguruan Tinggi dalam Sistem Kredit Semester (SKS) \& Sumber Belajar," Journal Al-Maktabah, Jurnal Komunikasi dan Informasi Perpustakaan, Volume 2, No.2, (Oktober 2000), 122.

6 Arif Gunawan, Darwanto dan Nazrul Rizal A. Lubis, "Pengembangan Koleksi pada Perpustakaan Pusat Penelitian dan Pengembangan Perikanan (Collection Development on Library of Research Center and Fisheries Development)," Jurnal Puri, Pusat Penelitian dan Pengembangan Perikanan Volume 2, Juli 2016. http:// www.ejournal-balitbang.kkp.go.id/index.php/jp, (akses pada tanggal 18 Oktober 2019, jam 19.34.

7 Sutarno NS, Manajemen Perpustakaan: Suatu Pendekatan Praktik,... 114. 
Pengembangan koleksi bertujuan untuk menambah, meningkatkan jenis bahan bacaan, serta meningkatkan mutunya sesuai dengan kebutuhan masyarakat pemakai. ${ }^{8}$ Pada sisi yang lain, jika koleksi terus bertambah, sedangkan ruangan, rak dan tempat penyimpanan tidak dikembangkan, maka pada suatu saat nanti perpustakaan akan penuh. Koleksi yang sudah relatif lama dan tidak terpakai lagi sebaiknya didata dan di tata kembali. Untuk menghindari keadaan demikian, maka dalam kegiatan pengembangan koleksi harus disertai kegiatan penyiangan. Untuk memisahkan koleksi yang sudah kadaluarsa, rusak dan tidak terpakai lagi, dikeluarkan dari jajarannya di rak buku, dan tempatnya dipergunakan untuk koleksi yang baru.

Koleksi Perpustakaan dalam UndangUndang no.43 tahun 2007 pasal 12 pada ayat 1 dan 2 menjelaskan bahwa: a). Koleksi perpustakaan diseleksi, diolah, disimpan, dilayankan, dan dikembangkan sesuai dengan kepentingan pemustaka dengan memperhatikan perkembangan teknologi informasi dan komunikasi. b). Pengembangan koleksi perpustakaan sebagaimana dimaksud pada ayat (1) dilakukan sesuai dengan standar nasional perpustakaan. ${ }^{9}$

Evans dalam Jurnal Nurintan menjelaskan tentang Information Transfer Work yang dapat dilakukan oleh perpustakaan. Tahapannya diawali dengan identifikasi dimana merupakan tahap mencari kebutuhan. Selanjutnya adalah seleksi yaitu tahap menentukan skala prioritas kebutuhan. Kemudian akuisisi yaitu tahap pengadaan. Selanjutnya merupakan persiapan dimana terjadi tahap pengolahan informasi yang diikuti dengan organisasi atau pengaturan informasi. Penyimpanan dan temu kembali informasi adalah tahap selanjutnya yang diikuti dengan interpretasi, yaitu tahap pengenalan penggunaan sistem informasi.

\footnotetext{
8 Ibid., 115.

9 Undang-Undang Republik Indonesia Nomor 43 Tahun 2017 tentang Perpustakaan, Bab IV pada Pasal 12.
}

Kemudian tahapan penggunaan dimana terjadi tahap asistensi penggunaan dan layanan yang terakhir yaitu penyebaran informasi. ${ }^{10}$

\section{Disabilitas}

Disabilitas merupakan istilah baru pengganti penyandang cacat. Menurut Kamus Besar Bahasa Indonesia, penyandang diartikan sebagai seseorang yang menderita (menyandang) sesuatu. Sedangkan disabilitas adalah cacat atau ketidakmampuan yang diserap dari bahasa Inggris yaitu Disability (disabilities). ${ }^{11}$ Pada tahun 1995 definisi yang digunakan adalah kehilangan atau abnormalitas anatomis, fungsi atau struktur psikologis atau fisiologis, derajat keparahan merujuk pada besarnya ketidakmampuan yang bearti keterbatasan (permanen) atau menurunnya kemampuan beraktivitas normal sebagai akibat suatu penyakit, sebab-sebab sejak didalam kandungan atau kecelakaan. Sedangkan pada tahun 1998 definisinya adalah setiap orang yang mengalami kecacatan sehingga mengganggu atau mendapatkan rintangan dan hambatan baginya untuk melakukan sesuat secara selayaknya. ${ }^{12}$

Penyandang disabilitas (person with disabilities) adalah mereka yang mengalami gangguan, kesulitan atau hambatan dalam melaksanakan aktivitas atau fungsi tertentu sehingga mereka membutuhkan alat bantu khusus, modififkasi lingkungan atau teknikteknik alternatif tertentu unutk dapat belajar dan berpartisipasi secara penuh dan efektif dalam kehidupan bermasyarakat. Penyandang disabilitas diantaranya adalah:

\footnotetext{
10 Nurintan Cynthia Tyasmara. Jurnal Pengembangan Koleksi Perpustakaan: Tantangan dan Pembelajaran Sepanjang Hayat, Perpustakaan UI, 2016, di bawah "http://lib.ui.ac.id/digital 2016-9 20435953-NurintanPengembanganKoleksi2.pdf (akses pada tanggal 17 Oktober 2019, jam 02.23.

11 Departemen Pendidikan Nasional, Kamus Besar Bahasa Indonesia Pusat Bahasa, (Jakarta: Gramedia Pustaka Utama, 2008), 132.

12 Irwanto dkk, Jurnal Analisis Situasi Penyandang Disabilitas di Indonesia: Sebuah Desk-Review, Pusat Disabilitas, Fakultas IImu-IImu Sosial dan Politik, Universitas Indonesia, Depok, Australian Goverment, 2010, 5.
} 
a). Tunanetra (hambatan pada fungsi penglihatan). b). Tunarungu (hambatan pada fungsi pendengaran dan bicara). c). Tunadaksa (hambatan pada fungsi fisik-motorik). d). Gangguan spektrum autis, dan lain-lain.

Penyandang disabilitas mempunyai hakhak baik dari perindividu maupun yang sudah terkandung di dalam Undang-Undang no.8 tahun 2016 yaitu hak untuk hidup, hak untuk bebas berstigma, hak untuk masalah privasi, hak untuk keadilan dan perlindungan hukum, hak untuk mendapatkan dan memperoleh informasi serta hak-hak lainnya.

Individu disabilitas membutuhkan cara, alat dan kondisi lingkungan tertentu supaya mereka dapat menjalani kegiatan dan aktivitas lainnya secara mudah dan aman. Dalam mengakses informasi, tunanetra perlu difasilitasi untuk menggunakan peralatan yang menekankan kepada fungsi auditif (pendengaran) dan tactile (peradaban). Tunarungu membutuhkan media visual supaya dapat mengakses informasi secarta mudah dan efektif. Tunadaksa membutuhkan modifikasi alat dan lingkungan fisik supaya mereka dapat melakukan aktivitas dan mobilitas secara mudah dan aman. Autis membutuhkan pendekatan khusus agar dapat berkomunikasi dan berinteraksi dengan orang lain secara efektif. Demikian juga dengan tipe disabilitas lainnya. Mereka masing-masing membutuhkan modifikasi yang berbeda.

Didalam buku yang ditulis oleh Akhmad Soleh menyampaikan bahwa UIN Sunan Kalijaga Yogyakarta sebagai universitas inklusif menyediakan berbagai fasilitas dan layanan bagi mahasiswa difabel, yaitu: ${ }^{13}$ a). Pusat Studi dan Layanan Difabel dengan fasilitas multimedia bagi difabel netra. b). Perpustakaan multimedia untuk mahasiswa difabel netra (tersedia di Blind Corner). c). Al-Qur'an Braille (30 juz).

13 Akhmad Soleh, Aksesibilitas Penyandang Disabilitas terhadap Perguruan Tinggi: Studi Kasus di Empat Perguruan Tinggi Negeri di Yogyakarta, (Yogyakarta: LkiS Printing Cemerlang, 2016), 164. d). Dosen yang sensitif terhadap kebutuhan khusus mahasiswa difabel (lebih komunikatif, lebih proaktif). e).Gedung dan ruang yang secara terus-menerus diusahakan untuk mudah diakses. f). Masalah teknis yang terkait dengan layanan terhadap difabel diatur tersendiri oleh fakultas atau unit masing-masing.

Perpustakaan merupakan salah satu tempat layanan publik yang harus mampu memberikan pelayanan terbaik kepada pengguna, tidak terkecuali pada perpustakaan perguruan tinggi. Akses untuk semua pengguna disabilitas ke setiap perpustakaan menjadi standar baku yang di keluarkan oleh IFLA (International Federation of Library Associations and Institutions). IFLA adalah sebah organisasi federasi yang terbentuk dari berbagai instansi perpustakaan dalam ruang lingkup internasional. Salah satu standar baku yang dikeluarkan oleh IFLA adalah standar kelayakan perpustakaan dalam melayani difabel. ${ }^{14}$

Perancangan standar oleh IFLA sebagai cara atau referensi praktis untuk semua jenis perpustakaan baik itu bersifat perpustakaan umum, perguruan tinggi, sekolah maupun perpustakaan khusus untuk menilai tingkat aksesibilitas yang ada di gedung, layanan, ketersediaan koleksi serta program dan lain sebagainya, serta untuk meningkatkan aksesibilitas yang diperlukan. Namun memang untuk membuat perpustakaan yang mudah di akses oleh para penyandang disabilitas memerlukan sumber daya ekonomi yang cukup besar. Untuk jumlah pendanaan yang minim, dan demi tercapainya aksesibilitas bagi penyandang disabilitas diperlukan perubahan sikap dan pemikiran staf dengan cara-cara baru.

IFLA memberikan solusi pada proses evaluasi baik untuk pengembangan koleksi, penyediaan gedung, layanan dan lain

14 Birgitta Irvall dan Gyda Skat Nielsen. "Acces to Libraries for person with Disabilities-Cheklist". (IFLA Profesional Report, 2015), dalam "IFLA" (di bawah) http://www.Ifla.org diakses tanggal 10 Desember 2019, jam 13.54 . 
sebagainya yaitu memasukan atau melibatkan perwakilan dari kelompok disabilitas. Agar dapat memberikan atau berkontribusi dalam tindakan peningkatan proses yang ada di perpustakaan serta perencanaan selanjutnya yang akan dilakukan oleh perpustakaan.

Dasarnya setiap perpustakaan di dunia berbeda, terutama dari segi bangunannya, yang di peruntukkan untuk para disabilitas. Namun IFLA menawarkan bahwa staf perpustakaan menerapkan hukum dan peraturan terkait di setiap negara atau menguji dengan pengguna penyandang disabilitas. Namun hal tersebut bisa berubah-ubah, namn yang utama yaitu fokus pada masalah yang paling penting saat ini, yaitu menjadikan kesetaraan akses bagi semua orang tanpa memandang kecacatan dengan memperhatikan dan mengevaluasi bangunan, layanan serta koleksinya. Perpustakaan dijadikan salah satu pusat layanan untuk membuat orang-orang penyandang cacat (disabilitas) merasa diterima di perpustakaan. ${ }^{15}$

Pada penelitian yang dilakukan oleh Marwiyah, SriRohyatiZ danLabibahZaindalam Tesis Ema Puji Lestari menyatakan bahwa di perpustakaan UIN Sunan Kalijaga dalam aspek fisik sudah memiliki potensi untuk berkembang dan beberapa sarana sudah terakomodir untuk di akses oleh mahasiswa disabilitas. Namun pada sarana lainnya untuk pemustaka difabel masih perlu di perbaiki yaitu tidak adanya lift untuk memudahkan pemustaka difabel dalam mengakses dan temu kembali informasi, media belajar masih kurang seperti jumlah koleksi yang dapat diakses, belum adanya staf yang memang ahli dalam memberikan layanan pada mahasiswa disabilitas, serta layanan khusus bagi pemustaka difabel. ${ }^{16}$

15 Ibid.

16 Ema Puji Lestari, Aksesibilitas Perpustakaan Bagi Difabel Berdasarkan pada Standar IFLA di UPT. Balai Layanan Perpustakaan "Grhatama Pustaka" BPAD DIY, Tesis yang di Publikasikan, (Yogyakarta: Pascasarjana UIN Sunan Kalijaga, 2017).

\section{HASILPENELITIANDANPEMBAHASAN}

Perpustakaan perguruan tinggi merupakan perpustakaan yang seharusnya menjadi perpustakaan yang ramah difabel. Pengembangan koleksi merupakan suatu proses universal untuk perpustakaan karena setiap perpustakaan akan membangun koleksi yang kuat demi kepentingan pengguna perpustakaan. ${ }^{17} \quad$ Untuk melaksanakan pengembangan koleksi perpustakaan secara terarah, perlu adanya ketentuan yang jelas sebagai pegangan bagi selektor dan pelaksana lainnya dalam pengembangan koleksi. Evans dalam buku Pengembangan Koleksi yang ditulis oleh Yuyu Yulia dan Janti Gristinawati Sujana menggambarkan proses pengembangan koleksi yang terdiri dari 6 komponen kegiatan yang terdiri dari, Analisis masyarakat dalam hal ini masyarakat pengguna, kebijakan seleksi, seleksi, pengadaan, penyiangan, dan evaluasi. ${ }^{18}$

Pada pembahasan ini, penulis akan menjelaskan dan mengkorelasikan teori evans yaitu tentang tahapan pengembangan koleksi yang penulis fokuskan kepada mahasiswa disabilitas atau mahasiswa yang berkebutuhan khusus pada Perguruan Tinggi UIN Sunan Kalijaga Yogyakarta. Proses pengembangan koleksi di perpustakaan Perguruan Tinggi UIN Sunan Kalijaga Yogyakarta dengan beberapa tahap yaitu:

\section{Analisis Masyarakat Pengguna}

Menganalisis masyarakat pengguna pada perpustakaan UIN Sunan Kalijaga Yogyakarta dilakukan dengan masuknya katalog dari distributor terkait dengan mata kuliah yang ada di semua fakultas di UIN Sunan Kalijaga Yogyakarta. Mengetahui kebutuhan mahasiswa melalui proses oleh mahasiswa part time yang di pandu oleh pihak fakultas dalam penyeleksi katalog dan kebutuhan mahasiswa. Analisis kebutuhan masyarakat pengguna yaitu khususnya mahasiswa disabilitas diberlakukan

\footnotetext{
17 Yuyu Yulia dan Janti Gristinawati Sujana, Pengembangan Koleksi Ed. I, (Jakarta: Universitas Terbuka, 2010), 8. 18 Ibid.
} 
sama dengan mahasiswa yang lainnya pada umumnya. Menganalisis kebutuhan sesuai dengan topik perkuliahan yang sedang berlangsung. Apakah distributor menyediakan buku yang menjadi sumber dan penunjang sumber pembelajaran di UIN Sunan Kalijaga Yogyakarta. Sehingga hal tersebut dapat membantu tercapainya proses belajar mengajar dalam pemenuhan kebutuhan ilmu pengetahuan oleh seluruh mahasiswa UIN Sunan Kalijaga Yogyakarta.

\section{Kebijakan Pengembangan Seleksi}

Kebijakan pengembangan koleksi akan menjadi sumber rujukan utama apabila terjadi perseteruan antarpihak baik di dalam perpustakaan maupun dengan pihak luar perpustakaan dalam hal yang terkait dengan masalah koleksi. Kebijakan merupakan sebuah mekanisme komunikasi dengan populasi yang dilayani perpustakaan, sebaik terhadap mereka yang memberikan dana kepada perpustakaan.

Banyak perpustakaan atau pusat informasi yang tidak mempunyai kebijakan pengembangan koleksi secara tertulis namun mempunyai koleksi yang baik. Hal ini dikarenakan pustakawannya yang berperan kuat, cerdas, dan termotivasi dengan komitmen yang tinggi terhadap perpustakaan dan koleksinya. Namun tidak semuanya mampu bertahan dalam bekerja tanpa adanya bentuk tertulisnya, sehingga apa yang direncanakan dan kebijakan dalam pengembangan koleksi tersebut diabaikan.

Kebijakan pengembangan koleksi didasari oleh beberapa asas berikut, yaitu, kerelevanan (relevan dengan aktivitas yang telah diprogramkan oleh perpustakaan sehingga memudahkan pencapaian kinerja perpustakaan yang memuaskan para stakeholders).

\section{Berorientasi kepada Kebutuhan Pengguna} (harus memenuhi kebutuhan pengguna). Kelengkapan(lengkapdalam artiterkaitdengan kebutuhan para pengguna utama perpustakaan walaupun secara hakiki sudah diketahui bahwa tidak mungkin bagi sebuah perpustakaan dapat memenuhi semua kebutuhan penggunanya). Kemutakhiran (pengadaan dan pembaharuan bahan pustaka yang menjadi koleksi sebagai bentuk perkembangan ilmu pengetahuan dan teknologi mutakhir). Kerja Sama (hasil kerja sama semua pihak yang berkepentingan dalam pengembangan koleksi dengan harapan pengembangan koleksi dapat berdaya guna dan berhasil guna).

Dari beberapa asas yang telah dijelaskan diatas, maka sangat jelas tahapan proses pengembangan koleksi perpustakaan di UIN Sunan Kalijaga Yogyakarta melakukan tahapan tersebut yaitu pada proses kebijakan pengembangan koleksi. Perpustakaan UIN Sunan Kalijaga Yogyakarta melakukan kebijakan secara tertulis. Baik dari buku maupun bahan pustaka yang tersedia bagi mahasiswa disabilitas pada sebuah perpustakaan perguruan tinggi, yang akan banyak pro dan kontra (bagian prodi dan institusi) tentang apa yang boleh dibaca oleh mahasiswa dan apa yang tidak boleh dibaca publik. Jika perpustakaan tersebut tidak mempunyai kebijakan, maka pustakawan akan terombang-ambing dalam keinginan berbagai tugas. Sehingga perlu adanya kebijakan pengembangan koleksi seperti yang dilakukan di perpustakaan UIN Sunan Kalijaga Yogyakarta.

\section{Seleksi Bahan Pustaka}

Seleksi bahan pustaka yang dilakukan di perpustakaan UIN Sunan Kalijaga Yogyakarta terkhusus untuk mahasiswa disabilitas merupakan hal terpenting yang dilakukan. Seleksi bahan pustaka dilakukan dengan mempertimbangkan jenis bahan pustaka, mutu bahan pustaka demi kemajuan pengetahuan mahasiswa serta yang paling cocok untuk dijadikan bahan koleksi di perpustakaan UIN Sunan Kalijaga Yogyakarta. Kebutuhan mahasiswa disabilitas terhadap proses temu kembali informasi merupakan masalah utama yang dihadapi, karena harus adanya penunjang 
dalam hal tersebut yaitu disediakannya ilmu pengetahuan dan proes temu kembali informasi melalui media, khususnya media elektronik. Sehingga, proses seleksi bahan pustakanya sama dengan mahasiswa pada umumnya. Namun yang melainkannya adalah proses temu kembali informasi dan medianya.

\section{Pengadaan Bahan Pustaka}

Setelah katalog masuk dari distributor menuju pihak perpustakaan, kemudian pihak perpustakaan menyampaikan kepada pihak program studi terkait katalog kebutuhan mahasiswa tersebut, dan pihak program studi dibantu oleh mahasiswa part time untuk penyeleksian katalog tersebut terkait dengan kebutuhan mahasiswa. Setelah katalog tersebut dipilih oleh dosen-dosen serta masukan dari mahasiswa terkait bahan koleksi, kemudian dikembalikan kepada bagian koleksi. Setelah itu kemudian diseleksi dan diverifikasi dengan beberapa pertimbangan seperti apakah sudah ada di perpustakaan UIN Sunan Kalijaga Yogyakarta, serta masalah pendanaan. Semuanya sudah terlewati, kemudian masuk kepada proses pengadaan bahan pustaka yang dibutuhkan sesuai dengan analisis kebutuhan pengguna yaitu mahasiswa UIN Sunan Kalijaga Yogyakarta.

\section{Penyiangan koleksi pustaka}

Penyiangan koleksi pustaka pada perpustakaan UIN Sunan Kalijaga juga melalui tahapan ini. Penyiangan bahan pustaka dilakukan untuk menilai bahan pustaka apakah sudah tidak diperlukan lagi atau ada perubahan dan perkembangan. Penyiangan bahan koleksi dilakukan karena beberapa hal, yaitu apakah isinya sudah tidak relevan dengan program perguruan tinggi, bahan perpustakaan yang isinya sudah usang, bahan perpustakaan yang sudah ada edisi barunya pada katalog dari distributor, adanya bahan pustaka yang sudah tidak lengkap, jumlah eksemplarnya terlalu banyak, dan bahkan fisiknya sudah rusak.

\section{Evaluasi Bahan Pustaka}

Menurut Depdiknas evaluasi adalah upaya untuk menilai daya guna dan hasil guna koleksi dalam memenuhi kebutuhan akademik pemustaka serta program perguruan tinggi. Evaluasi harus selalu dilaksanakan dengan teratur supaya koleksi sesuai dengan perubahan dan perkembangan program perguruan tinggi. ${ }^{19}$ Perpustakaan UIN Sunan Kalijaga Yogyakarta melakukan evaluasi bahan pustaka dengan mengikuti dan mengetahui perubahan dalam katalog yang diberikan oleh distributor,meningkatkan nilai informasi dalam perkembangan pengetahuan mahasiswa, mengetahui kelemahan koleksi bahan pustaka.

\section{KESIMPULAN}

Penulis telah mengkolerasikan teori yang ditawarkan oleh Evans terkait dengan tahapan pengembangan koleki dengan kegiatan pengembangan koleksi yang dilakukan di perpustakaan UIN Sunan Kalijaga Yogyakarta dengan mempertimbangkan standar yang telah dikeluarkan oleh IFLA (International Federation of Library Associations and Institutions) yaitu perpustakaan merupakan salah satu tempat layanan publik yang harus mampu memberikan pelayanan terbaik kepada pengguna, tidak terkecuali pada perpustakaan perguruan tinggi serta memberikan akses untuk semua pengguna disabilitas ke setiap perpustakaan. Setelah melalui beberapa wawancara dengan dua narasumber dan hasil observasi peneliti, diperoleh kesimpulan bahwa tahapan pengembangan koleksi yang ditawarkan oleh Evans dengan 6 komponen kegiatan yang terdiri dari Analisis masyarakat dalam hal ini masyarakat pengguna, kebijakan seleksi, seleksi, pengadaan, penyiangan, dan evaluasi. Teori ini diterapkan di perpustakaan UIN Sunan Kalijaga Yogyakarta. Mahasiswa yang normal dan penyandang disabilitas di UIN Sunan Kalijaga Yogyakarta memiliki kebutuhan

19 Depdiknas, Perpustakaan Perguruan Tinggi, (Jakarta: Depdiknas, 2004), 67. 
pengetahuan yang sama, dikelompokkan dalam kelas yang sama. Namun dalam hal ini yang membedakannya adalah cara mengakses yang dilakukan oleh mahasiswa disabilitas dengan penambahan bantuan yaitu melalui media audio dan visual dan lainnya.

\section{DAFTAR PUSTAKA}

Departemen Pendidikan Nasional. Kamus Besar Bahasa Indonesia Pusat Bahasa. Jakarta: Gramedia Pustaka Utama. 2008.

Departemen Pendidikan Nasional. Perpustakaan Perguruan Tinggi. Jakarta: Depdiknas. 2004.

Gunawan, Arif. Darwanto dan Nazrul Rizal A. Lubis. "Pengembangan Koleksi pada Perpustakaan Pusat Penelitian dan Pengembangan Perikanan (Collection Development on Library of Research Center and Fisheries Development)." Jurnal Puri. Pusat Penelitian dan Pengembangan Perikanan Volume 2. Juli 2016. Di bawah http://www.ejournalbalitbang.kkp.go.id/index.php/jp, akses pada tanggal 18 Oktober 2019.

Irvall, Birgitta. Gyda Skat Nielsen. "Acces to Libraries for person with DisabilitiesCheklist". (IFLA Profesional Report, 2015). dalam "IFLA" di bawah http:// www.Ifla.org. diakses tanggal 10 Desember 2019.

Irwanto dkk. Jurnal Analisis Situasi Penyandang Disabilitas di Indonesia: Sebuah Desk-Review. Pusat Disabilitas. Fakultas Ilmu-Ilmu Sosial dan Politik. Universitas Indonesia. Depok. Australian Goverment. 2010. 5.
Nurintan Cynthia Tyasmara. Jurnal Pengembangan Koleksi Perpustakaan: Tantangan dan Pembelajaran Sepanjang Hayat. Perpustakaan UI. 2016, di bawah http:// lib.ui.ac.id/ digital 2016-9 20435953- Nurintan-Pengembangan Koleksi2.pdf. di akses pada tanggal 17 Oktober 2019. jam 02.23.

Puji Lestari, Ema. Aksesibilitas Perpustakaan Bagi Difabel Berdasarkan pada Standar IFLA di UPT. Balai Layanan Perpustakaan "Grhatama Pustaka" BPAD DIY, Tesis yang di Publikasikan, Yogyakarta: Pascasarjana UIN Sunan Kalijaga, 2017.

Qalyubi, Syihabuddin dkk. Dasar-dasar ilmu Perpustakaan dan Informasi, Yogyakarta: Jurusan Ilmu Perpustakaan dan Informasi Fakultas Adab, 2003.

Soleh, Akhmad. Aksesibilitas Penyandang Disabilitas terhadap Perguruan Tinggi: Studi Kasus di Empat Perguruan Tinggi Negeri di Yogyakarta, Yogyakarta: LkiS Printing Cemerlang, 2016.

Sutarno NS, Manajemen Perpustakaan: Suatu Pendekatan Praktik, Jakarta: Sagung Seto, 2006.

Syamsudin, Anwar. "Manajemen dan Peran Perpustakaan Perguruan Tinggi dalam Sistem Kredit Semester (SKS) \& Sumber Belajar." Journal Al-Maktabah, Jurnal Komunikasi dan Informasi Perpustakaan, Volume 2, No.2. Oktober 2000. 122. 
Perpustakaan Universitas Nahdatul Ulama

Surabaya, Tujuan dan Fungsi

Perpustakaan Perguruan Tinggi https:// library.unusa.ac.id/2016/10/20/ tujuandan-fungsi-perpustakaan-perguruantinggi/, diakses pada 18 Oktober 2019, jam 20.31 .

Tyasmara, Nurintan Cynthia. Jurnal Pengembangan Koleksi Perpustakaan: Tantangan dan Pembelajaran Sepanjang Hayat. Perpustakaan UI. 2016.

Undang-Undang Republik Indonesia Nomor 43 Tahun 2017 tentang Perpustakaan, Bagian Keempat. Pasal 24.

Undang-Undang Republik Indonesia Nomor 43 Tahun 2017 tentang Perpustakaan, Bab IV pada Pasal 12.

Yulia, Yuyu dan Janti Gristinawati Sujana. Pengembangan Koleksi Ed. I, Jakarta: Universitas Terbuka, 2010. 